\title{
Analysis of the health risk assessment of chlorinated organic pollutants in the water source for food processing in Nanning

\author{
Wang Lili ${ }^{1, \text { a }}$, Kong Song ${ }^{2, b}$,Gao Cong ${ }^{2, c}$, LiangJian ${ }^{1, d}$, Liu Xinliang ${ }^{\text {2,e }}$ \\ ${ }^{1}$ Guangxi Nanning Waterworks Co.,Ltd., Guangxi Nanning 530031, P.R. China \\ ${ }^{2}$ College of Light Industry and Food Engineering, Guangxi University, Nanning 530004, P.R. China \\ a16126805@qq.com, bsong_kong@hotmail.com, ${ }^{\mathrm{c}} 304496440 @ q q . c o m,{ }^{\mathrm{e}} x \mathrm{inliang.liu@163.com}$
}

\begin{abstract}
Keywords: Food processing, Water resources, Health risk assessment, Chlorinated organic pollutants, Non-carcinogenic risk assessment.

Abstract. 6 kinds of chlorinated organic pollutants, such as chlorobenzene, 1, 2- dichlorobenzene, 1, 4 - dichlorobenzene, 1,2,4-trichlorobenzene, 2, 4 - dichlorophenol and pentachlorophenol, were analyzed in 5 main water source for 50 food processing companies in Nanning. The health risk assessment of the chlorinated organic pollutants were also studied by the drinking water assessment method of United States Environmental Protection Agency (USEPA). The results showed that all the chlorinated organic pollutants were not detected in the water example, as the concentrations are lower than the detection limit of the instruments. The instrumental detection limit were used as the concentrations of the pollutants to value the health risk assessment, and the results showed that the hazard index (HI) of total non-carcinogenic risks of the pollutants were below 1.0, suggesting that the water posed negligible health risk on local residents.
\end{abstract}

\section{Introduction}

In recent years, the water pollution is becoming more and more serious in China. The quality and safety of drinking water and food processing water has been widely attented. Some contaminination would be ingested by the food processing water or beverage processing water, which inevitably theaten human health. Therefore, it is significant to analysis the health risk assessment of food processing water sources. Health risk assessment, which is relate to the amount of pollutants, can be used to describ the risk of pollutants for human health quantitatively.[1-3]

As chlorobenzene, 1,2-dichlorobenzene, 1,4-dichlorobenzene, 1,2,4-trichlorobenzene, 2,4dichlorophenol, pentachlorophenol are toxic. It can cause sicknesses of liver, kidney or nervous system, if they were taken in for a long time. There is also the possibility of induced lymphosarcoma, lung cancer, colorectal cancer, cervical cancer and other cancers[4, 5]. These chlorinated benzene and chlorinated phenols has been posted on the US Environmental Protection Agency (USEPA) website, which are classified as priority control pollutants. The policy has been adopted in China to control the pollutants, chlorobenzene and 1,2-dichlorobenzene, in water sources, and the requirement was much strict $[2,6]$. Therefore, the threat of the organic pollutants, including chlorinated benzenes and chlorinated phenols, can not be ignored.

There have been lots researches and vestigations about health risk assessment of water quality in China, but most were focused on the toxic substances in drinking water, such as polycyclic aromatic hydrocarbon (PAHs) [8-11], heavy metal ions[12,13], ect. However, there is seldom reseach on the water or water source for food or food processing.

The chlorinated organic pollutants were tested in the water sources for food processing in Nanning, including chlorobenzene, 1,2-dichlorobenzene, 1,4-dichlorobenzene, 1,2,4trichlorobenzene, 2,4-dichlorophenol, pentachlorophenol 6 typical chlorinated benzene and chlorinated phenols. Their health risk assessments were investigated and analysised and evalued via US Environmental Protection Agency (USEPA) exposure risk assessment method.

The potential health risk assessment was analyzed, and the impacts of the pollutants on the exposed population health risks were also studied, which could be a reference and theoretical basis for risk assessment of water source for food processing. 


\section{Materials and methods.}

Materials. GC-7890 Gas Chromatograph(USA Agilent Company) and MSD-5975C Mass Detector(USA Agilent Company) were used. The other equipments were used, such as Auto Spe06C Automatic SPE Concentrator ( Xiamen Reeko Instrument Co.Ltd.), Turbovap LV Concentrated nitrogen blowing instrument (USA Zymark Company), 1100 PHLC High performance liquid chromatography (USA Agilent Company with diode array detector(VWD).

The chlorobenzene, 1,2,4-trichlorobenzene, 1,2-dichlorobenzene, 1,4-dichlorobenzene, pentachlorophenol, 2,4-dichlorophenol and other standard samples used in experiment are HPLC grade By J \& K Technology Co.Ltd. Methanoland ethyl acetate are HPLC grade supplied by Merck, Germany.

Experimental Methods. The study investigated 50 manufacturers for food processing or beverage in Nanning. The water intake points are distributed in 5 locations of Yong River in Nanning, as shown in Fig. 1. Water samples were conlected and storaged in sealed bottle in refrigerator kept at $2-5^{\circ} \mathrm{C}$ to be detected.

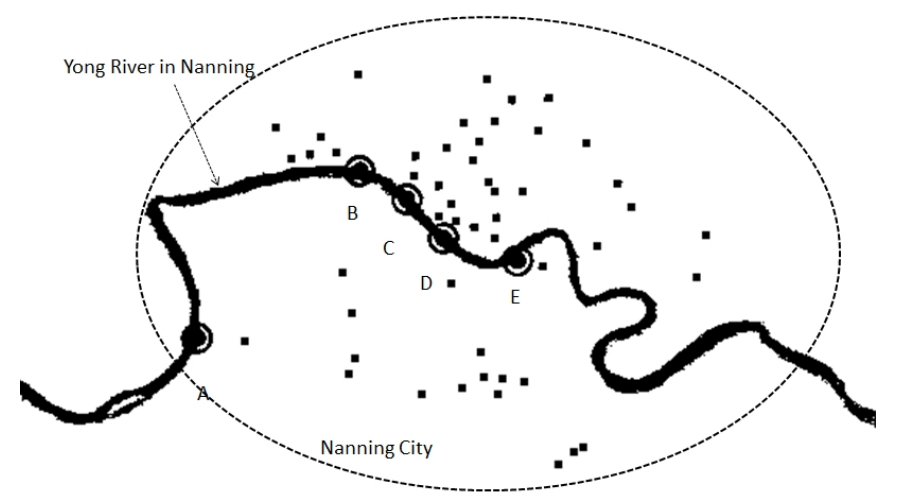

Fig .1. 50 food processing and beverage manufacturers near Nanning and their water sources intake point ( $\mathbf{a}$ food processing and beverage manufacturers; $O$ water intake point $(\mathrm{A}-\mathrm{E})$ ).

Chlorobenzene, 1,2-dichlorobenzene, 1,4-dichlorobenzene and 1,2,4-trichlorobenzene were detected by GC-MS. 2,4-dichlorophenol and pentachlorophenol were detected by HPLC[14, 15].

\section{Analysis Methods.}

Detection of pollutants.

Pretreatment. $5.0 \mathrm{~mL}$ water sample was purged at $35^{\circ} \mathrm{C}$ for $2 \mathrm{~min}$, and kept transfer line temperature at $150{ }^{\circ} \mathrm{C}$. Resolution temperature is $250{ }^{\circ} \mathrm{C}$, Resolution for $2 \mathrm{~min}$, Blow dry for $2 \mathrm{~min}$, Blow dry temperature is $65{ }^{\circ} \mathrm{C}$, desorption for $2 \mathrm{~min}$, Baking temperature is $250{ }^{\circ} \mathrm{C}$, Baking for $2 \mathrm{~min}$.

GC-MS analysis. Agilent HP-1701 Capillary separation columns $(30 \mathrm{~m} \times 0.25 \mathrm{~mm}, 0.25 \mu \mathrm{m})$; Inlet temperature: $200^{\circ} \mathrm{C}$;Programmed temperature: Set the initial temperature $40{ }^{\circ} \mathrm{C}$, Holding $2 \mathrm{~min}$; Heating at a rate of $20^{\circ} \mathrm{C} / \mathrm{min}$ to $120{ }^{\circ} \mathrm{C}$, Holding for $3 \mathrm{~min}$. The carrier gas $(\mathrm{He})$ flow rate: $1.0 \mathrm{~mL} / \mathrm{min}$,Split ratio $20: 1$; Detector temperature: quadrupole temperature is $150{ }^{\circ} \mathrm{C}$, Transfer lin temperature: $280{ }^{\circ} \mathrm{C}$, Ion source temperature: $230{ }^{\circ} \mathrm{C}$. Chlorobenzene characteristic ion 112.

Detection method of 1,2,4-trichlorobenzene, 1,2-dichlorobenzene, 1,4-dichlorobenzene. Take $500 \mathrm{~mL}$ water sample, and add $6 \mathrm{~mol} / \mathrm{L}$ hydrochloric acid to adjusted $\mathrm{pH}$ down to 2, then add $5 \mathrm{~mL}$ methanol. Autospe-06C automatic solid phase extraction concentrators was used to concentrate the examples with $\mathrm{C} 18$ extraction column extraction. It was washed by $5 \mathrm{~mL}$ of ethyl acetate and $5 \mathrm{~mL}$ methylene chloride. The examples were concentrated to about $0.5 \mathrm{~mL}$.

GC-MS analysis. Agilent DB-1701 capillary separation column $(30 \mathrm{~m} \times 0.25 \mathrm{~mm}, 0.25 \mu \mathrm{m})$ was used. The inlet temperature was $250{ }^{\circ} \mathrm{C}$. Temperature program was set as following. The initial 
temperature was at $70{ }^{\circ} \mathrm{C}$ holding for $3 \mathrm{~min}$. Then the temperature rised to $260^{\circ} \mathrm{C}$ at rate of $10^{\circ} \mathrm{C} / \mathrm{min}$ with holding for $2 \mathrm{~min}$. The carrier gas (helium gas) flow rate was kept at $1.0 \mathrm{~mL} / \mathrm{min}$ with split ratio at $1: 1$. Quadrupole temperature was kept at $150^{\circ} \mathrm{C}$. Transfer line temperature was $280{ }^{\circ} \mathrm{C}$, and ion source temperature: $230{ }^{\circ} \mathrm{C}$. The injection volume was $1.0 \mu \mathrm{L}$. 1,2-dichlorobenzene characteristic ion and 1,4-dichlorobenzene characteristic ion were 146. 1,2,4- trichlorobenzene characteristic ion was 180 .

Detection method of pentachlorophenol, 2, 4-dichlorophenol. Take 500mL water sample, then add $0.5 \mathrm{~mol} / \mathrm{L}$ sulfuric acid adjust $\mathrm{pH}$ to $1.5-2$ with Auto spe-06C Automatic solid phase extraction concentrators extract and concentrated. Then it was treated with tetrahydrofuran, and concentrated $0.5 \mathrm{~mL}$. A small amount of methanol was used to transfer it to a $10 \mathrm{~mL}$ colorimetric tube, and added $0.1 \mathrm{~mL}$ acetic acid and $4.5 \mathrm{~mL}$ deionized water. Then methanol was added to sure the volume to $10 \mathrm{~mL}$, mixed.

Chromatographic column was used with the conditions. Waters spherisorb ODS2 C18 column $(4.6 \mathrm{~mm} \times 250 \mathrm{~mm} \times 5 \mu \mathrm{m})$ was used with flowing phase ratio as $88 \%$ flowing phase $\mathrm{A}$ (Methanol / 1\% acetic acid) and 12\% flowing phase B(pure Water / 1\% acetic acid). The flowing phase flow rate was $1.0 \mathrm{~mL} / \mathrm{min}$, and injection volume $100.0 \mu \mathrm{L}$. UV detection wavelength was $295 \mathrm{~nm}$. Column temperatur was at $40{ }^{\circ} \mathrm{C}$.

Health Risk Assessment Methods. There are a lot of methods to evaluate the health risk of pollutants in water, especially for drinking water at home and abroad. However, there is seldom report about the health assessment methods for food processing water or beverage processing water. Therefore, this article intends to use the the quality evaluation model recommended on United States Environmental Protection Agency(USEPA) site, to evaluate health analysis several organochlorine contaminants, which may exist in food processing water. This could be a reference and theoretical basis for risk assessment of water source for food processing.

Risk Assessment Model. According to the carcinogenicity of substances to humans, the risk of environmental pollutants on human health can be divided into non-carcinogenic risk and carcinogenic risk. Non-carcinogenic risk is not harmful to human health in a certain dose threshold range, so the health risk study is just considerred to detect more than the dose threshold valuse. The evaluation of carcinogenic risk is that as long as the trace substances exposed to the people, it would cause carcinogenic hazards to human health, and it also could cause the non carcinogenic risk. The carcinogenicities of 1,2-dichlorobenzene, 2,4-dichlorobenzene and 1,2,4-trichlorobenzene are not clear. International Cancer Research Institute (IARC) did not liste them as carcinogen, and USEPA did not announced its carcinogenicity data. Though chlorobenzene, 2,4-dichlorophenol and pentachlorophenol have the potential hazard to cause cancer, USEPA did not explicitly listed them as carcinogens $[6,16]$.

If the pollutants existed in water, which used as the source of food processing without being treated, it could be take into human body through food or beverage. Therefore, the noncarcinogenic health risks of water pollutants should be considered, as if they were ingested directly.

Non-Carcinogenic Risk Index. USEPA defined non-carcinogenic risk index as dose threshold for the response of organisms to non-carcinogens. If the dose is lower than the threshold, it is considered to have no adversely affect on human health[6]. Non-carcinogenic risk index is usually expressed by the risk index (HI). HI is defined as the ratio of long-term daily intake dose caused by exposure to the reference, which can be calculated as Eq.1.

\section{$H I=I n / R f D$}

Where $H I$ is non-carcinogenic risk index for some non-carcinogens absorbed by drinking way. In is the dose of non-carcinogenic for long-term daily intaked, $\mathrm{mg} /(\mathrm{kg} \cdot \mathrm{d}) . R f D$ is reference dose of non-carcinogens absorbed through drinking pathway, $\mathrm{mg} /(\mathrm{kg} \cdot \mathrm{d})$. The study assumes that 6 kinds of pollutants could be ingested through the digestive system for long time. The daily intake dose (In) can be calculated by the formula USEPA used for the evaluation of the non carcinogenic risk of drinking water[6]. The Eq.2 was as following.

$$
m=(C \times I R \times E D \times A F) /(B W \times A T \times L T)
$$


Where $C$ is the concentration of pollutant, $\mathrm{mg} / \mathrm{L} . I R$ is the average daily intake rate, take $0.5 \mathrm{~L} /$ day. $A F$ is the exposure frequency,take 365 days (one year). $E D$ is the duration of exposure, take 30 years. $B W$ is the average body weight, take the average $61.5 \mathrm{~kg}$ of the average weight for men and women. $A T$ is average contact time,take 10950days (30 years). $L T$ is average life expectancy, take China's average life expectancy of 70 years.

Calculation results: $H I \geqslant 1$ indicates a risk, $H I<1$ indicates no risk.

Table 1. Toxicity parameters of six kinds of benzene and phenol organic pollutants.

\begin{tabular}{|c|c|c|c|}
\hline Organics name & $\begin{array}{l}\mathrm{RfD} \\
(\mathrm{mg} / \mathrm{kg} \cdot \mathrm{d} \\
)\end{array}$ & $\begin{array}{l}\text { NOAEL } \\
(\mathrm{mg} / \mathrm{kg} \cdot \mathrm{d} \\
)\end{array}$ & UF \\
\hline Chlorobenzene & 0.02 & 27.25 & 1000 \\
\hline 1,2-dichlorobenzene & 0.002 & 0.857 & 3000 \\
\hline $\begin{array}{l}\text { 1,4- } \\
\text { Dichlorobenzene }\end{array}$ & 0.8 & 0.75 & 100 \\
\hline $\begin{array}{l}1,2,4- \\
\text { trichlorobenzene }\end{array}$ & 0.01 & 0.148 & 1000 \\
\hline 2,4-dichlorophenol & 0.003 & 0.3 & 300 \\
\hline pentachlorophenol & 0.005 & 1.5 & 300 \\
\hline
\end{tabular}

Margin of Exposure evaluation of exposure. Margin of Exposure (MOE) is an important indicator to measure the non-cancer risk[6]. The Eq.3 can be expressed as following (3):

MOE $=$ NOAEL $/ \mathrm{nMOE}=$ NOAEL $/ \mathrm{n}$

While the bigger MOE valued is, the smaller risk of chemicals will be. The risk can be obtained by comparing $\mathrm{MOE}$ with the uncertainty factor (UF). If $\mathrm{MOE}<\mathrm{UF}$, it implies a significant risk. If $\mathrm{MOE} \geqslant \mathrm{UF}$, it indicates small risk[17]. NOAEL represent the non-toxic concentration, $\mathrm{mg} /(\mathrm{kg} \bullet \mathrm{d})$.

Parameter Value. The chemical and toxicity parameters of the pollutants are used the parameters in USEPA integrated risk information system (IRIS) database [6], see in Table 1.

\section{Results and discussion}

Through the test of all samples of the water, the concentrations of pollutants were below the limit of detectability, thus they were not detected. The limit of detectability and recovery rate of the method are shown in Table 2.

Table2. The limit of detection and marked recovery rate of 6 kind of organic compounds

\begin{tabular}{lll}
\hline Organics name & $\begin{array}{l}\text { The limit of } \\
\text { detection } \\
(\mathrm{mg} / \mathrm{L})\end{array}$ & $\begin{array}{l}\text { recovery } \\
\text { rate }(\%)\end{array}$ \\
\hline $\begin{array}{l}\text { Chlorobenzene } \\
\text { 1,2-dichlorobenzene }\end{array}$ & $\begin{array}{l}0.0001 \\
0.002\end{array}$ & $\begin{array}{l}101 \pm 0.7 \\
100 \pm 0.5\end{array}$ \\
$\begin{array}{l}\text { 1,4- } \\
\begin{array}{l}\text { Dichlorobenzene } \\
\text { 1,2,4- }\end{array}\end{array}$ & 0.004 & $99 \pm 0.9$ \\
trichlorobenzene & 0.0001 & $105 \pm 2.4$ \\
$\begin{array}{l}\text { 2,4-dichlorophenol } \\
\text { pentachlorophenol }\end{array}$ & 0.001 & $102 \pm 1.5$ \\
\hline
\end{tabular}

These 6 kinds of organic compounds were not detected in the water samples in our research, therefore, it assumes that the limit of detectability was the maximum concentration of the organic pollutants in water samples, and their health risks was investgated. The calculation method was 
used as discribled and of the evaluation model described earlier in this article, the results shown in Table 3.

Table3. Non-carcinogenic risk assessment results of 6 kinds of organic compounds

\begin{tabular}{llll}
\hline $\begin{array}{l}\text { organic } \\
\text { compounds }\end{array}$ & $\begin{array}{l}\text { dose of } \\
\text { daily } \\
\text { intake } \\
\text { In }\end{array}$ & $\begin{array}{l}\text { non- } \\
\text { carcinogeni } \\
\text { c risk index } \\
\text { HI }\end{array}$ & $\begin{array}{l}\text { Redunda } \\
\text { ncy of } \\
\text { exposure } \\
\text { MOE }\end{array}$ \\
\hline $\begin{array}{l}\text { Chlorobenzene } \\
1,2-\end{array}$ & $1.16 \times 10^{-8}$ & $5.81 \times 10^{-7}$ & $2.35 \times 10^{9}$ \\
dichlorobenzene & $2.32 \times 10^{-7}$ & $1.16 \times 10^{-4}$ & $3.69 \times 10^{6}$ \\
$\begin{array}{l}1,4- \\
\text { Dichlorobenzene }\end{array}$ & $4.65 \times 10^{-7}$ & $5.81 \times 10^{-7}$ & $1.61 \times 106$ \\
$\begin{array}{l}1,2,4- \\
\text { trichlorobenzene }\end{array}$ & $1.16 \times 10^{-8}$ & $1.16 \times 10^{-6}$ & $1.27 \times 10^{7}$ \\
$\begin{array}{l}\text { 2,4-dichlorophenol } \\
\text { pentachlorophenol }\end{array}$ & $1.16 \times 10^{-7}$ & $3.87 \times 10^{-5}$ & $2.58 \times 10^{6}$ \\
\hline
\end{tabular}

According to USEPA's definition of non-carcinogenic risk index of toxic substances in drinking water, non-carcinogenic risk index is the threshold of non-carcinogen for organism. If noncarcinogenic risk index HI smaller than 1or redundancy MOE bigger than UF, it can be considered that there is no adverse effects on health [18].

In table 3, typical chlorinated benzene and chlorinated phenols organic compounds, including chlorobenzene, 1,2-dichlorobenzene, 1,4-dichlorobenzene, 1,2,4-trichlorobenzene, 2,4dichlorophenol and pentachlorophenol, were investgated in water samples of 5 water resources for food processing or beverage in Nanning, and their non-carcinogenic risk indexes are smaller than 1. Redundancy of exposure MOE of these kinds of chlorinated benzene and chlorinated phenols organic compounds were all larger then their corresponding uncertainty factor UF. Thus it can be inferred there was minimal non-carcinogenic risk of local residents for chlorobenzene, 1,2dichlorobenzene, 1,4-dichlorobenzene, 1,2,4-trichlorobenzene, 2,4-dichlorophenol, pentachlorophenol in these water sources of 50 food processing companies in Nanning, which could be negligible.

\section{Conclusion}

In this paper, the organic chloride of five water sources for 50 food processing and beverage companies in Nanning were detected, and those 6 kinds of chlorobenzene and chlorophenol organics were not detected. In the method, detection limits were assumed to be the maximum concentrations of organic chlorides, the non-carcinogenic risk assessment of these 6 kinds of organic chloride were investgated according to the US Environmental Protection Agency (USEPA) for drinking water health risk assessment methods. The results indicated that these 6 kinds of organic chloride have minimal non-carcinogenic risk for human, which could not cause the harm effect for human health.

\section{Acknowledgements}

This work was financially supported by Project of Guangxi Education Department (YB2014014) and Scientific research and technological development projects (Gui Ke Gong 14251009).

\section{Reference}

[1] YANG Yan, Lu Xiaosong, Li Dinglong. Journal of environment and health. Forum Vol. 04 (2014), p. 357. 
[2] Xie Chunyu, Sun Liping, Chen Xu, et al. Environmental engineering. Forum Vol. s1 (2014), p.876.

[3] Luo Jinhong. Human health risk assessment of drinking water source [D]. East China Normal University,2012.

[4] Wang Li. Distribution characteristics and health risk assessment of toxic pollutants in typical villages and towns [D]. Southern Medical University, 2012.

[5] Thomas S, Sarfaraz S, Mishra L C, et al. World Journal of Microbiology \& Biotechnology. Forum Vol. 18 (2002), p. 57.

[6] Information on http://www.epa.gov/iris/rfd.htm.

[7] Hattemer-Frey H A, Travis C C. Archives of Environmental Contamination and Toxicology. Forum Vol. 18 (1989), p. 482.

[8] Fan Qinghua, Li Gang, Wang Beixin, et al. China Environmental Monitoring. Forum Vol. 01 (2012), p. 6.

[9] Liu Xin. Distribution and health risk assessment of polycyclic aromatic hydrocarbons and their derivatives in drinking water [D]. Southwest University, 2011.

[10] Wan Yiwen, Kang Tianfang. Environmental Pollution and Control. Forum Vol. 04 (2010), p. 16.

[11] Zhao Xiao. Study on regional health risk in Shijiazhuang Sewage Irrigation District [D]. Wuhan University, 2005.

[12] Wei Yihua Zhang Dawen Zhang Li He Junhai Luo Linguang. Journal of ecology, Forum Vol. 24 (2015).

[13] Liu Xinyao, Xian Ping, Li Xiaoming, et al. Journal of Guangxi University (Natural Science edition). Forum Vol.03(2014),p.586.

[14] Liang Jian, Weng Weiman, Ge Li, et al. Journal of Guangxi University (Natural Science edition). Forum Vol. 06(2012),p.1126.

[15] Wei FuSheng in : Water and wastewater monitoring analysis method .Fourth edition . China Environmental Science Press, (2002).

[16] Crosby D G. Pure and Applied Chemistry. Forum Vol. 53(5)(1981), p.1051.

[17] Hu Jianying. In: Risk assessment of chemical substances. Science Press, (2010).

[18] Zheng Jiang, Wang Ling, Liu Ning, et al. Environmental monitoring management and technology. Forum Vol.(05)(2010),p.26. 